\title{
Editorial
}

\section{How determinants of health determine health?}

\author{
Ramsha Khan ${ }^{1}$, Muhammad Salman Haider Qureshi ${ }^{2 *}$ \\ ${ }^{1}$ Department of Health Promotion and Public Health, University of West London, United Kingdom \\ ${ }^{2}$ Department of Public Health, Khyber Medical University, Pakistan
}

Received: 02 December 2017

Revised: 14 January 2018

Accepted: 16 January 2018

\section{*Correspondence: \\ Dr. Muhammad Salman Haider Qureshi, E-mail: pmc.salmanqureshi@gmail.com}

Copyright: (C) the author(s), publisher and licensee Medip Academy. This is an open-access article distributed under the terms of the Creative Commons Attribution Non-Commercial License, which permits unrestricted non-commercial use, distribution, and reproduction in any medium, provided the original work is properly cited.

The determination of health can be done by many factors such as social, physical, economic, environment, life style and also by the help of interaction between characteristics of people. The experts believe that instead of health care that is required to assure a healthy and sound population, those broader determinants are relatively more important. ${ }^{1}$ The most common factors that affect the people health include, the residential place, genetically factors, the work and home environment, the social interaction with friends or family, sex, the level of the education, and also how much an individual earns. For example, the people who are less educated have more chances to develop health issues because of low selfesteem or lack of awareness. Physical environment plays an important role when considering good or bad health of individuals, that is they live in houses with dirty condition, then they are more likely to have ill health. On the other hand, clean environment promotes good health. In some cases, health may also be affected by how much people have access to health care services. ${ }^{2}$

The difference in distribution of determinants of health or health status between different groups of populations can be regarded as 'health inequality'. It can be further explained, for instance, the difference in the level of mobility between and younger and older population or disparities in death rate among rich and poor socioeconomic classes. ${ }^{2}$ However, there lies a difference between inequity and inequality in health. There are certain health inequalities that results from variation of biological determinants while other results from influence of external environment. Unlike inequality, inequity has got its ethical aspect which results from avoidable and unfair discrepancies that are present in health status.
Equity in health means that every person should have the right to acquire the best possible health in other words, if it's possible then no one should remain underprivileged from attaining best health. ${ }^{3}$ Equity deals with creating such health opportunities that are equal and thus trying to bring the discrepancies as much low as possible. ${ }^{4}$

Biological determinants of health are referred to the genetic makeup of the body. Although social, environmental and economic factors have a stronger impact on health, in some cases inherited factors can become the reason for developing certain disease or health issues in specific people. Studies proved that if the child is offered the most favorable conditions between the period of inception of pregnancy and age five, the progress of the brain demonstrates the positive results in life. $^{5}$

There are many examples of biological determinants of health such as sex, age and genetic factors. Age plays an important role on the impact of health, for example the health of the old people is biologically more likely to be poor as compared to the adolescents' health, this is because of the old age as it affects the mental and physical health. ${ }^{6}$ When considering sex, the different physical appearance and having different reproductive body organs, influence both men and women health in different way, for example women suffer from cervical cancer while men develop prostate cancer. Men are more likely to develop heart diseases in their early stages of life than women. ${ }^{7}$ This is because women have lower tendency to develop infection and also the presence of oestrogen helps the cholesterol level to be balanced. ${ }^{8}$ 
Genetic factors have stronger influence on predicting an individual's future health and it also increases the chances of a certain disease to be developed. For example, if the individual's family history has shown diabetes then the chances of suffering from diabetes will be increased in that individual. ${ }^{9}$ The impact of disability on person's health can be accessed by what problems they face in their daily life. For example, a person who is physically disabled may face problems in life in terms of access to transport, lack of job opportunities. Disabilities can also become the cause for many psychological problems for example disabled students might suffer from anxiety, depression, low self-esteem which may also affect their performance in study. ${ }^{10}$

When it comes to promoting health of the community, health services play an important role in the prevention and treatment of disease. They follow a care structure which involves activities like the use of mammography and immunization. In order to progress well in the future, this practice must continue. ${ }^{6}$

When viewing health, the environmental factors take a broader approach as it includes all the external and social factors. For example, the good and unpolluted environment of the house and work, safe and clean drinking, good transport, clean air, all these factors can result in achieving good health. ${ }^{2}$ According to an estimate from World Health Organisation, the unhealthy environment of house and work resulted in the death of around 12.6 million people in 2012, which is almost 1 in 4 of over-all worldwide death. Over 100 injuries and diseases have been caused by other environmental factors; ultraviolet radiation, soil, air and water pollution, change in climate and chemical exposures. ${ }^{2}$ This indicates a connection between poor or good health and the quality of house. According to recent estimate, NHS is spending $£ 1.4$ bn per annum because of poor housing. Damp houses may cause respiratory illness, poor or weak structure of the house may result in falls and trips which can then lead to serious injuries such as fractures. If the heating system is not very good, then the resident might get cold and become less active. ${ }^{11}$

Poverty may also become the cause for experience unhealthy housing conditions, as usually poor people cannot afford the good quality house. While on the other hand, rich people are more intend to live in healthy house. Poverty can also lead to living in an undeveloped area which does not able the resident to use all the resources thus resulting in less emissions which can contaminate the environment. This can be considered as an example of inequities. ${ }^{12}$

Air pollution is another environmental factor which also contributes to ill health. The higher exposure to air pollution may increase the chances of an individual to develop cardiovascular and respiratory diseases which results in higher rate of mortality. In 1952 in London, the cause of 4000 premature deaths in one week, and 8000 deaths in next following months, was extreme air pollution. ${ }^{13}$ The chances of obesity may increase in people who live in residential areas with poor designs, as they may have less resources such as parks, leaving them sedentary as they are not doing enough physical activity. Also the people may less socialize with other people which can lead to poor mental health. ${ }^{14}$

Poor transport is associated with accidents. Dependence on transport on daily basis can make a person less active which can then lead to childhood obesity, heart diseases, high blood pressure etc. Air pollution because of vehicles may increase the morbidity and mortality rate. A person may suffer from lung cancer which can then affect the quality of life. If the transport is not easily accessible and affordable then that can also affect the quality of life and individual's health. ${ }^{15}$ Noise pollution also influences our health. People who live near airports or other noise related areas, train station, suffer from disturbed sleep patterns which then results in less concentration, heart diseases, stress, depression. ${ }^{16}$

Many diseases can be prevented by paying attention on the reduction of environmental risk factors; poor housing, noise, air and water pollution. This can be done by taking few steps, for example promotion of protected water storage in houses, introducing and practising improved cleaning actions and also by managing well the toxic substances at work and in homes. ${ }^{2}$

Another determinant of health is lifestyle which can be described as a composition of habits, possessions and attitudes that are related with a specific group of people or individual. It is an overall pattern of behaviours related to health on the basis of voluntary selections made by people that are available to them with respect to the opportunities that they get in their lives. ${ }^{17}$

Physical activity and diet are the two important components of lifestyle. Being sedentary or lack of physical activity can affect the health for example can cause obesity and also the chances of cardiovascular diseases also increases. ${ }^{18}$ Elderly people are more likely to suffer from chronic disease and this is because they eat less fruits and vegetables which helps in the treatment and prevention of the diseases and also if they are retired, then it makes them less active. ${ }^{19}$ People smoke because of stress, not educated, adopted it from culture, family or friends. In China, every year, around one million smokers die because of smoking caused diseases and in 2020 this will probably be increased than two million. ${ }^{20}$ Smoking can cause lung cancer, heart disease, and also babies can be born with lower birth weight. Smoking can be associated with different social groups for example people who live in more underprivileged areas have higher tendency to smoke and have les chances to stop smoking as compared to the one who live in rich areas. Thus smoking in England can be seen as inequalities in health. The morbidity rate because of lung cancer, of both 
men and women who belong to poor area, are higher than those who belong to less deprived area.

The concept of sexual behaviour varies from person to person as it is different from the view of the professional person. That is why there is a probability that some people think that having involved in oral sex may not cause any harmful infections which is a wrong perception. Oral sex can also lead to many sexually transmitted diseases. It is very important to educate individuals about unsafe sexual activities. In the year 2011, in the UK alone, there were approximately 96,000 people who were infected with human immunodeficiency virus HIV. $^{21}$

Lastly, taking into consideration all the facts mentioned above, it has been clearly proven that the individual and community health can be affected by many factors for example sex, family history, genetics, housing conditions and lifestyle. All these factors are collectively regarded as determinants of health. Health can also be affected if the individual belongs to a certain group for example a poor person may be unable to afford a good house in a developed area, results in developing health issues by experiencing poor surrounding conditions and limited health facilities. Thus the differences between poor and rich groups should be avoided by providing equal opportunities for example having equal access to education can change individual attitudes towards the achievement of good possible health.

\section{REFERENCES}

1. Broader determinants of health. The King's Fund. 2018. Available at: https://www.kingsfund.org.uk/ projects/time-think-differently/trends-broader-determinants-health. Accessed on 19 December 2016.

2. Public Health, Environmental and Social Determinants of Health. World Health Organization. 2018. Available from: http://www.who.int/phe/en/. Accessed on 20 December 2016.

3. World Health Organization. Targets for health for all: targets in support of the European strategy for health for all. Copenhagen: WHO Office for Europe. 1985.

4. Whitehead M. The concepts and principles of equity and health. Health Promotion Int. 1991;6(3):217-28.

5. Canada P. What Makes Canadians Healthy or Unhealthy? Canada.ca. 2018. Available at: https://www.canada.ca/en/public-health/services/ health-promotion/population-health/what-determines-health/what-makes-canadians-healthyunhealthy.html. Accessed on 27 December 2016.

6. Determinants of Health. Healthy People 2020. Healthypeople.gov. 2018. Available from: https://www.healthypeople.gov/2020/about/foundati
on-health-measures/Determinants-of-Health.

Accessed on 27 December 2016.

7. Doyal L. Sex, gender, and health: the need for a new approach. BMJ: Br Med J. 2001;323(7320):1061.

8. Naidoo J, Wills J. Foundations for Health Promotion-E-Book. Elsevier Health Sciences; 2016.

9. Hernandez, Lyla M, Blazer DG. Genetics and Health. National Academies Press; 2006.

10. Shafiq H. Issue and Challenges Faced by Person with Disabilities. International Islamic University Malaysia, 2014

11. Roys M, Davidson M, Nicol S, Ormandy D, Ambrose P. The real cost of poor housing. Bre Press; 2010.

12. Environmental determinants of disease. Health Knowledge. 2011. Available at: https://www.health knowledge.org.uk/public-health-textbook/diseasecausation-diagnostic/2f-environment/environmentaldeterminants-disease. Accessed on 27 December 2016.

13. Kjellstrom T, Lodh M, McMichael T, Ranmuthugala G, Shrestha R, Kingsland S. Air and water pollution: burden and strategies for control.

14. World Health Organization (WHO). Review of evidence on housing and health. InFourth Ministerial Conference on Environment and Health. Geneva. The World Health Organization. Background document 2004: 5046267.

15. Haines A, McMichael T, Anderson R, Houghton J. Fossil fuels, transport, and public health: Policy goals for physical activity and emission controls point the same way. BMJ. 2000;321(7270):1168.

16. Holzman DC. Fighting noise pollution: a public health strategy. Environmental Health Perspectives. 2014;122(2):58.

17. Cockerham WC. Health Lifestyle Theory and the Convergence of Agency and Structure. J Health Social Behavior. 2005;46(1):51-67.

18. He XZ, Baker DW. Body mass index, physical activity, and the risk of decline in overall health and physical functioning in late middle age. American J Public Health. 2004;94(9):1567-73.

19. McNaughton SA, Crawford D, Ball K, Salmon J. Understanding determinants of nutrition, physical activity and quality of life among older adults: the Wellbeing, Eating and Exercise for a Long Life (WELL) study. Health Quality Life Outcomes. 2012;10(1):109.

20. Redmon P, Koplan J, Eriksen M, Li S, Kean W. The role of cities in reducing smoking in China. International J Environmental Res Public Health. 2014;11(10):10062-75.

21. Upton D, Thirlaway K. Promoting healthy behaviour: A practical guide. Routledge; 2014.

Cite this article as: Khan R, Qureshi MSH. How determinants of health determine health? Int J Sci Rep 2018;4(3):46-8. 